\title{
HDAC1 Regulates Fear Extinction in Mice
}

\author{
Sanaz Bahari-Javan, ${ }^{1,2}$ Andrea Maddalena, ${ }^{3 *}$ Cemil Kerimoglu, ${ }^{1,2 *}$ Jessica Wittnam, ${ }^{1}$ Torsten Held, ${ }^{1,2}$ Mathias Bähr, ${ }^{3}$ \\ Susanne Burkhardt,, ${ }^{1,2}$ Ivanna Delalle, ${ }^{4}$ Sebastian Kügler, ${ }^{3}$ Andre Fischer, ${ }^{1,2,4,5}$ and Farahnaz Sananbenesi ${ }^{1,2}$ \\ ${ }^{1}$ Department of Psychiatry and Psychotherapy, University Medical Center Göttingen, 37075 Göttingen, Germany, ${ }^{2}$ European Neuroscience Institute \\ Göttingen, 37077 Göttingen, Germany, ${ }^{3}$ Department of Neurology, Center for Molecular Physiology of the Brain, University Medicine Göttingen, 37073 \\ Göttingen, Germany, ${ }^{4}$ Department of Pathology and Laboratory Medicine, Boston University School of Medicine, Boston, Massachusetts 02118 , ${ }^{5} \mathrm{German}$ \\ Center for Neurodegenerative Diseases, DZNE Göttingen Germany, 37077 Göttingen, Germany
}

Histone acetylation has been implicated with the pathogenesis of neuropsychiatric disorders and targeting histone deacetylases (HDACs) using HDAC inhibitors was shown to be neuroprotective and to initiate neuroregenerative processes. However, little is known about the role of individual HDAC proteins during the pathogenesis of brain diseases. HDAC1 was found to be upregulated in patients suffering from neuropsychiatric diseases. Here, we show that virus-mediated overexpression of neuronal HDAC1 in the adult mouse hippocampus specifically affects the extinction of contextual fear memories, while other cognitive abilities were unaffected. In subsequent experiments we show that under physiological conditions, hippocampal $\mathrm{HDACl}$ is required for extinction learning via a mechanism that involves H3K9 deacetylation and subsequent trimethylation of target genes. In conclusion, our data show that hippocampal HDAC1 has a specific role in memory function.

\section{Introduction}

The acetylation of histone proteins is an important epigenetic mechanism that regulates gene expression and contributes to proper genome-environment interactions (Fischer et al., 2010). In the majority of cases, high levels of histone acetylation are associated with an active chromatin state that allows transcription, while deacetylated histone proteins are linked to inactive chromatin and gene silencing. Recent studies have demonstrated that neuronal histone acetylation is dynamically regulated in response to environmental stimuli that initiate memory formation (Levenson et al., 2004; Fontán-Lozano et al., 2008; Bousiges et al., 2010; Peleg et al., 2010). Moreover, deregulated histone acetylation has been implicated in various neuropsychiatric diseases such as Morbus Alzheimer, Huntington's disease, or schizophrenia (Sananbenesi and Fischer, 2009). Histone acetylation is regulated via the counteracting activity of histone acetyltransferases and histone deacetylases (HDACs) that add and remove acetyl

Received Jan. 6, 2012; accepted Feb. 7, 2012.

Author contributions: S.B.J., A.F., and F.S. designed research; S.B.J., A.M., C.K., J.W., T.H., S.B., S.K., and F.S. performed research; M.B. and I.D. contributed unpublished reagents/analytic tools; S.B.J. and F.S. analyzed data; S.B.J., A.F., and F.S. wrote the paper.

${ }^{*}$ A.M. and C.K. contributed equally to this work.

This work was supported by Deutsche Forschungsgemeinschaft (DFG) Grant SA1050/2-1 to F.S. The work was furthermore partially supported the EUYRI award of the European Science Foundation to A.F. S.B.J. is supported by DFG Grant SA1050/2-1, and A.F. and S.B.J. are members of the DFG clinical research group 241. A.M., S.B., and M.B. are supported by the European Community's Seventh Framework Programme FP7/2007-2013 under grant agreement number HEALTH-F5-2008-222925. The European Neuroscience Institute is jointly funded by the University Medicine Goettingen and the Max Planck Society.

The authors declare no competing financial interests.

Correspondence should be addressed to Farahnaz Sananbenesi, Department of Psychiatry and Psychotherapy, University Medical Center Göttingen, European Neuroscience Institute Göttingen, Grisebach Strasse 5, 37077 Göttingen, Germany. E-mail: fsananb@gwdg.de.

DOI:10.1523/JNEUROSCI.0079-12.2012

Copyright $\odot 2012$ the authors $\quad 0270-6474 / 12 / 325062-12 \$ 15.00 / 0$ groups from specific lysine residues within the $\mathrm{N}$ terminus of histone proteins (Kimura et al., 2005).

Targeting histone acetylation via the use of HDAC inhibitors was shown to have neuroprotective and neuroregenerative actions in animal models for neurodegenerative and neuropsychiatric diseases (Fischer et al., 2010). However, relatively little is known about the mechanisms that lead to altered histone acetylation during disease progression. Among the 11 HDAC proteins encoded in the mammalian genome, several studies have reported altered levels of HDAC1 during the pathogenesis of brain diseases. For example, Hdacl expression is upregulated in neurons under hypoxia conditions (Wang et al., 2011), and elevated levels of $H d a c 1$ have been observed in postmortem brain samples from schizophrenia patients (Benes et al., 2007; Sharma et al., 2008). Increased Hdacl expression was also observed in a mouse model for Huntington's disease (Quinti et al., 2010). However, mice that lack or overexpress neuronal HDAC1 from early developmental stages are viable and display normal memory function (Guan et al., 2009).

Thus, we hypothesized that an acute overexpression of HDAC1 in the adult brain may help to better understand the role of elevated HDAC1 expression in brain diseases. To this end, we developed a virus-mediated approach to overexpress neuronal HDAC1 in the adult hippocampus, a brain region affected during the pathogenesis of neuropsychiatric diseases. Explorative and depressive-like behavior, spatial and associative long-term memory formation, as well as working memory function were unaffected by elevated HDAC1 levels. However, we found that HDAC1 specifically regulates the extinction of contextual fear memories. Through a combination of behavioral and molecular experiments, we show that under physiological conditions hippocampal HDAC1 regulates extinction learning via a mechanism that involves $\mathrm{H} 3 \mathrm{~K} 9$ deacetylation and subsequent trimethylation 
of target genes. In conclusion, our data show that hippocampal HDAC1 activity regulates the extinction of contextual fear memories and might be implicated in the pathogenesis of anxiety diseases.

\section{Materials and Methods}

Animals. Three-month-old adult male C57BL/6 wild-type mice were housed under standard conditions with ad libitum access to food and water. All experiments were performed in accordance with the animal protection law and were approved by the District Government of Germany.

Contextual fear extinction. Behavior testing was performed as described previously (Sananbenesi et al., 2007) using TSE Systems apparatuses. In brief, fear conditioning was performed with a computerized fear conditioning system (TSE Systems) using a computer connected to a control unit containing a shock and a tone generator. Animals were allowed to explore the training cage for $3 \mathrm{~min}$ followed by a mild electric shock ( $2 \mathrm{~s}, 0.7 \mathrm{~mA}$ ). Context-dependent freezing, defined as the absence of movements other than those required for breathing, was assessed $24 \mathrm{~h}$ later. Extinction of contextual fear was performed on consecutive days, consisting of reexposure to the training context in a non-reinforced manner for $3 \mathrm{~min}$. In all experiments this extinction training protocol led to a significant reduction of freezing behavior. However, as described previously, the dynamics of fear extinction can vary among experiments (Sananbenesi et al., 2007; Agis-oa et al., 2011) and, thus, treatment groups should only be compared with the given control group.

Open field. Explorative behavior was analyzed using the open field test. Mice were placed in the center of an open arena (length $1 \mathrm{~m}$; width $1 \mathrm{~m}$; side walls $20 \mathrm{~cm}$ height) for $5 \mathrm{~min}$ and explorative behavior was recorded by a camera and analyzed using the VideoMot2 software (TSE Systems). Total distance traveled and the relative time spent in the center of the arena was quantified.

Novel object recognition test. The novel object recognition test was conducted in an open field arena (length $1 \mathrm{~m}$; width $1 \mathrm{~m}$; side walls $20 \mathrm{~cm}$ height). During the habituation period, mice were allowed to explore the empty arena for $5 \mathrm{~min}$ on three consecutive days. Twenty-four hours after habituation, mice were exposed to the familiar arena with two identical objects placed at an equal distance $(18 \mathrm{~cm}$ from the sidewalls) for 5 min for an additional $2 \mathrm{~d}$. Twenty-four hours after habituation to the two identical objects, mice were allowed to explore the open field in the presence of two new identical objects for 5 min followed by a retention period in the home cage for $5 \mathrm{~min}$. Meanwhile, one of the objects was replaced with a new object, and working memory was assessed by exposing the mice to this situation for $5 \mathrm{~min}$ by recording time spent exploring the new and old object using VideoMot2 software (TSE Systems). After $24 \mathrm{~h}$, the new object was replaced again by another new object to test long-term memory.

Cross-maze exploration test. The Cross-maze exploration test was performed to assess spatial working memory using a protocol previously described (Jawhar et al., 2012). Spontaneous alternation rates were revealed using a cross-maze made of black plastic material consisting of four arms arranged in a $90^{\circ} \mathrm{C}$ position (arm sizes: $30 \mathrm{~cm}$ length, $8 \mathrm{~cm}$ width, and $15 \mathrm{~cm}$ height) rising from a central place measuring $8 \times 8 \mathrm{~cm}$. One test session consisted of $10 \mathrm{~min}$ in which the mice were placed in the center and allowed to explore freely each arm of the cross-maze. Arm entries were recorded using a camera and VideoMot2 software (TSE Systems). Percentage of alternation was used as readout for memory strength, defining successive entries into the four arms in overlapping quadruple sets (e.g., 1, 3, 2, 4 or 2, 3, 4, 1 but not 1,2,3,1). The alternation percentage was calculated as the percentage of actual alternations to the possible number of arm entries.

Prepulse inhibition of acoustic startle response. Startle reactivity was measured using an apparatus from TSA GmbH according to a previously described protocol (Radyushkin et al., 2009). In short, mice were placed individually in a small cylindrical cage with an integrated stainless floor grid $(80 \times 40 \times 45 \mathrm{~cm})$ to restrict major movements and placed on a sensitive transducer platform in a sound-attenuating cabinet. Acoustic stimuli were delivered through loudspeakers above the cage and startle response signals sampled by the software running on a PC. One testing session consisted of a $3 \mathrm{~min}$ habituation phase to $65 \mathrm{~dB}$ background noise followed by a $2 \mathrm{~min}$ baseline recording. After baseline recording, mice were exposed to six pulse-alone trials with startle stimuli of $120 \mathrm{~dB}$ intensity and $40 \mathrm{~ms}$ duration to decrease the influence of within-session habituation and to scale down the initial startle response to a stable plateau [data not included in analysis of prepulse inhibition (PPI)]. Startle reaction to an acoustic stimuli was recorded beginning with the startle stimuli for a time window of $100 \mathrm{~ms}$ and stored for further analysis. For PPI of startle reactivity, startle stimuli of $120 \mathrm{~dB}$ for $40 \mathrm{~ms}$ were applied either alone or preceded with a non-startling stimulus of 5,10 , or $15 \mathrm{~dB}$ over the $65 \mathrm{~dB}$ background noise $(70 \mathrm{~dB}, 75 \mathrm{~dB}, 80 \mathrm{~dB})$. Between each prepulse and pulse-alone stimulus, an interval of $100 \mathrm{~ms}$ with background noise was used. Each trial (startle pulse alone, pulse preceded by 70,75 , or $80 \mathrm{~dB}$, or no stimulus) was presented in a pseudorandom order with intertrial intervals ranging from 8 to $22 \mathrm{~s}$. The amplitude of the startle response (expressed in arbitrary units) was defined as the maximum force (Max G) detected during a reaction to a $120 \mathrm{~dB}$ acoustic stimulus during the recording window. Maximum amplitudes were averaged for each mouse separately for all types of trials (i.e., stimulus alone or stimulus preceded by a prepulse). Prepulse inhibition (expressed as percentage) was calculated as the percentage of the startle response using the following formula: Prepulse inhibition $(\%)=$ $100-[($ startle amplitude after prepulse and pulse)/(startle amplitude after pulse only $\left.)^{\circ}-100\right]$.

Porsolt forced swim test. Porsolt forced swim test is a well characterized paradigm to analyze depression-like behavior in rodents and was performed as described previously(Kuczera et al., 2011). Briefly, mice were placed in a vertical plastic cylinder (diameter $20 \mathrm{~cm}$ ) filled with room temperature water, and immobility was measured for $5 \mathrm{~min}$ with a stop-watch.

Morris water maze. The Morris water maze training was performed in a circular tank (diameter $1.2 \mathrm{~m}$ ) and a platform hidden below the surface of opaque water. The swimming path of mice was recorded using a video camera and analyzed by the VideoMot2 software (TSE Systems). Each mouse was subjected to one session per day consisting of four trials in which the mouse was put into the water maze subsequently from a different location represented by different spatial cues. If the mouse failed to reach the hidden platform within $60 \mathrm{~s}$, it was gently guided to it. Mice were allowed to remain on the platform for $15 \mathrm{~s}$. Twenty-four hours after the last training session, mice were subjected to one memory test (probe trial) in which the platform was removed and each mouse was left in the maze for $1 \mathrm{~min}$. The relative time spent in the quadrant where the platform was previously located and the number of crosses through the region outlining the former location of the platform were used as a readout for the memory strength.

Rotarod test. The Rotarod test was performed to test motor function using the Rota Rod V4.02 System (TSE Systems). After four habituation sessions (10 rpm constant), each mouse was exposed to four testing sessions (5-40 rpm uniform acceleration for $4 \mathrm{~min}, 40 \mathrm{rpm}$ constant for $1 \mathrm{~min}$ ) on two consecutive days on the rotating rod. Performance was measured by the length of time each mouse spent on the rod.

Cannulation and bilateral hippocampal injections. For pharmacological intervention, microcannulae were inserted into the dorsal hippocampus as previously described (Peleg et al., 2010). In brief, bilateral microcannulae were inserted into the hippocampus: anteroposterior $-1.70 \mathrm{~mm}$ relative to bregma, lateral $\pm 1 \mathrm{~mm}$, dorsoventral $2 \mathrm{~mm}$ from skull. MS275 (pyridin-3-ylmethyl 4-(2-aminophenylcarbamoyl)benzylcarbamate; Calbiochem), an HDAC inhibitor that inhibits HDAC1 at the nanomolar range but has a 100 -fold lower $\mathrm{EC}_{50}$ toward HDAC2/HDAC3 and no activity toward the other HDACs (Hu et al., 2003; Khan et al., 2008), was prepared as a $10 \mathrm{mg} / \mathrm{ml}$ stock solution in DMSO. For intrahippocampal injections, MS-275 was diluted to a concentration of 750 $\mathrm{ng} / \mu \mathrm{l}$ in artificial CSF and injected bilaterally into the hippocampus $(0.5$ $\mu \mathrm{l}, 0.5 \mu \mathrm{l} / \mathrm{min}$ ). As such, the total amount of MS-275 injected in the brain was $375 \mathrm{ng} / \mathrm{hemisphere.} \mathrm{Based} \mathrm{on} \mathrm{previous} \mathrm{work,} \mathrm{we} \mathrm{assumed} \mathrm{a} \mathrm{dilution}$ factor of 100-fold upon hippocampal injection (Sananbenesi et al., 2007). In this case the final concentration of MS-275 in the hippocampus (hippocampal volume is $\sim 28 \mathrm{~mm}^{2}$ ) (Peirce et al., 2003) would be 0.3 
$\mathrm{ng} / \mathrm{mm}^{2}$, which is well in range to allow specific inhibition of HDAC1. For the injection of virus particles $\left(1.0 \times 10^{8}\right.$ transducing units), surgery was prepared as described above. For the HDAC1 knockdown experiment with siRNA, siSTABLE Control siRNA from Thermo Scientific Dharmacon targeted against HDAC1 was diluted in PBS and prepared with the HiPerfect transfection reagent from Qiagen to a final concentration of $500 \mu \mathrm{M}$ according to a protocol previously described (Zovoilis et al., 2011). siSTABLE Non-targeting siRNA was used as a negative control (scramble).

Immunoblot analysis and immunohistochemistry. For crude lysates, brain tissue was homogenized in TX buffer (50 mm Tris, $150 \mathrm{~mm}$ $\mathrm{NaCl}, 2 \mathrm{M}$ EDTA, 1\% Triton-X and protease inhibitors) incubated for $15 \mathrm{~min}$ at $4^{\circ} \mathrm{C}$, and centrifuged for $10 \mathrm{~min}(10,000 \mathrm{rpm})$. The supernatant was used for immunoblotting. For analyzing protein levels in AAV-GFP and AAV-HDAC-GFP mice, proteins were isolated using TRI reagent according to the manufacturer's instructions (Sigma-Aldrich). Immunoblots were performed using fluorescent secondary antibodies and data were quantified using an Odyssey Imager (LI-COR). Antibodies were diluted either in $0.5 \%$ milk PBT or $0.5 \%$ milk TBT, respectively. Subcellular fractionation was performed using the ProteoExtract Subcellular Proteome Extraction Kit (Calbiochem). Immunostaining was performed as described previously (Fischer et al., 2004; Sananbenesi et al., 2007) and analyzed using a Leica SP2 confocal microscope. The following antibodies were commercially purchased and used in the mentioned concentrations: GAPDH, 1:5000, Millipore Bioscience Research Reagents; Synaptophysin (Svp38) 1:1000, Sigma-Aldrich; NeuN 1:1000, Millipore Bioscience Research Reagents; Cy3labeled antibody (goat anti-rabbit 1:500; Jackson ImmunoResearch); Alexa Fluor 488labeled antibody (donkey anti-mouse 1:500; Invitrogen).

Chromatin immunoprecipitation. For chromatin immunoprecipitation (ChIP) the DNA-shearing Kit and OneDay ChIP Kit protocol from Diagenode was used according to the manufacturer's protocol. The following modifications were made to optimize the procedure for hippocampal tissue. Tissue was homogenized with twice the amount of the different buffers indicated. DNA shearing was performed using the Bioruptor (Diagenode) with the following settings ( $25 \mathrm{~min}$, High, $30 \mathrm{~s} \mathrm{ON}, 30 \mathrm{~s}$ OFF). Sheared chromatin samples were incubated for $60 \mathrm{~min}$ with $4 \mu \mathrm{l}$ of antibody. Subsequently, the antibody-antigen complex was further incubated with preblocked beads and an extra $500 \mu \mathrm{l}$ of ChIP buffer for $60 \mathrm{~min}$. Afterward, the beads were washed twice instead of the single wash step stated in the protocol. Precipitated DNA was analyzed on a Bioanalyzer (Agilent). Antibodies used for ChIP were as follows: HDAC1 and H3K9me3 from Diagenode; Sir2 from Millipore, KMT1A/SUV39H1, HDAC2, and HDAC3 from Abcam; mSin3b from Santa Cruz Biotechnology.

Quantitative real-time PCR. Total RNA was isolated using TRI reagent (Sigma-Aldrich) according to the manufacturer's instructions. Quantitative real-time PCR (qPCR) was performed using a Roche LightCycler 480. cDNA was generated using the Transcriptor High Fidelity cDNA Synthesis Kit (Roche) and qPCR for c-Fos and Egr-2 genes was performed using the Roche Universal Probe Library (UPL). Data were normalized to the housekeeping gene hypoxanthine phosphoribosyltransferase (Hprt) or the corresponding input in the case of ChIP experiments. For the ChIP experiments, qPCR for specific genomic DNA was performed using the SYBR Green I Master Kit (Roche). The primers designed for c-Fos and Egr-2 promoters are shown in Table 1.
Table 1. Primers designed for C-Fos and Egr-2 promoters

\begin{tabular}{ll}
\hline PCR primer & Sequence \\
\hline - cFos promoter $R$ & CCCCCTAAGATCCCAAATGT \\
c-Fos promoter $L$ & GTCGCGGTTGGAGTAGTAGG \\
Egr-2 promoter $R$ & CATGTGACGGCAAAGCTG \\
Egr-2 promoter $L$ & GCCAGGAGTTGCTGGTGTAG \\
\hline
\end{tabular}

Figure 1. HDAC1 expression in the adult hippocampus. $A$, HDAC1 protein levels were analyzed in different brain areas by immunoblotting. $\boldsymbol{B}$, Representative immunoblot images showing that hippocampal HDAC1 is highly enriched in the nuclear fraction. C, Representative immunoblot analysis showing HDAC1 protein in the postmortem human brain obtained from patients the image depicts the representative pattern observed in 4 individuals. For $20 \mu \mathrm{m}$. Ecx, Entorhinal cortex; Hip, hippocampus; Hy, hypothalamus; Pfc, prefrontal cortex; Sep, septum; Str, striatum; CA1, CA2, CA3, hippocampal subfields; cc, corpus callosum; DG, dentate gyrus; py, pyramidal cell layer. Error bars indicate SEM.

Statistical analysis. The data were analyzed by unpaired Student's $t$ test and one- or two-way ANOVA, including repeated measurements whenever appropriate. Errors are displayed as SEM.

\section{Results}

AAV-mediated overexpression of HDAC1 in the hippocampus

In line with previous data (Broide et al., 2007), we observed robust HDAC1 expression in the adult brain. Immunoblot and immunohistochemical analysis revealed that HDAC1 is expressed at high levels in neuronal nuclei of mouse hippocampal neurons. Since our study is focused on the hippocampus, using mice as model organisms, we wondered whether significant levels of HDAC1 are found in the human hippocampus. Immunoblot data revealed that high levels of HDAC1 are found in the human hippocampus (Fig. 1).

We hypothesized that an acute overexpression of HDAC1 in the adult brain may help to better understand the role of elevated HDAC1 expression observed in various pathological conditions (Benes et al., 2007; Sharma et al., 2008; Quinti et al., 2010; Wang et al., 2011). To address this question, we used a virus-mediated gene transduction method that allowed us to overexpress HDAC1 in hippocampal neurons of adult mice. We generated adeno-associated viruses that express HDAC1 fused with GFP (AAV-HDAC1-GFP) or GFP alone (AAV-GFP) under the neuron-specific synapsin 1 promoter (Kügler et al., 2003). AAV- 
A

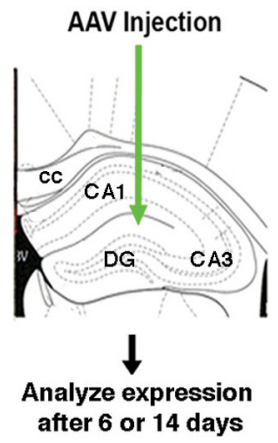

D

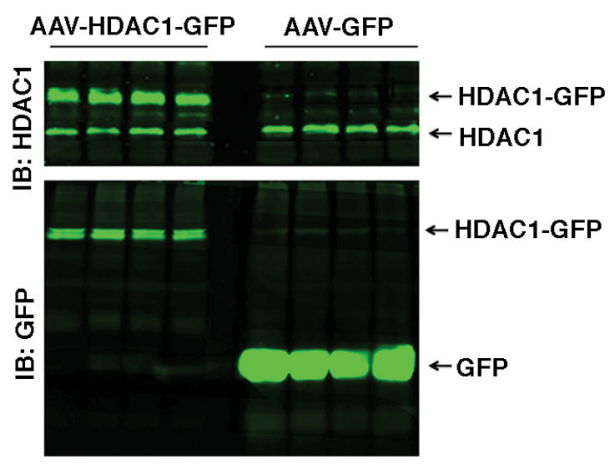

$\mathbf{F}$

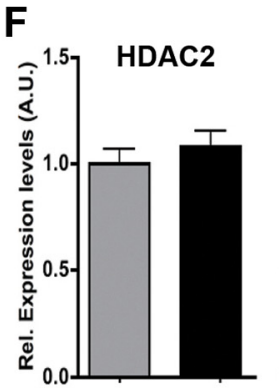

B

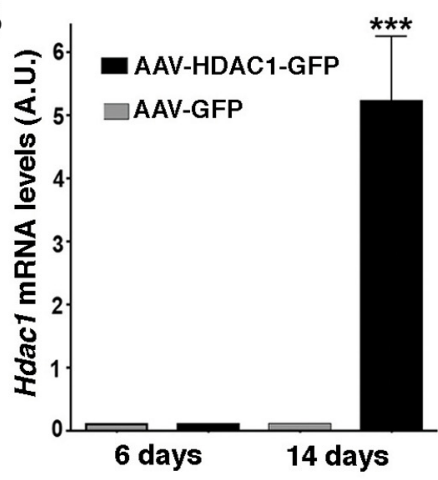

C

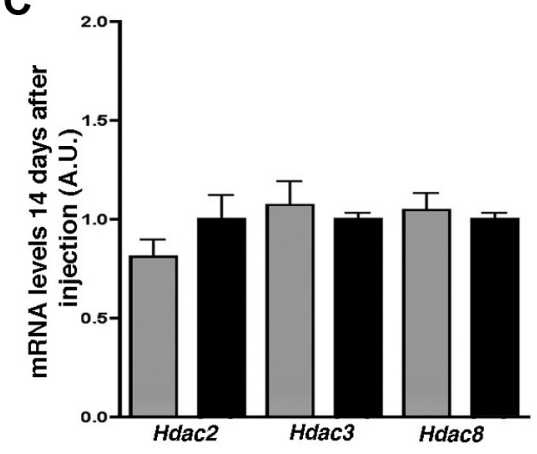

E

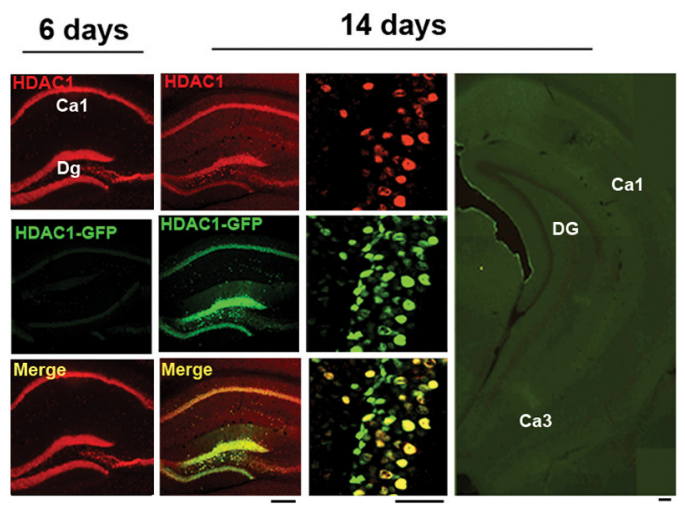

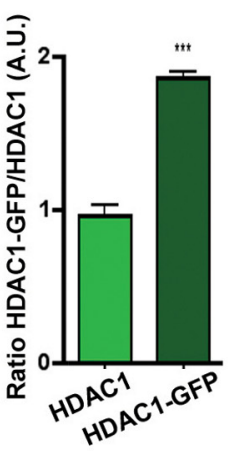

- AAV-HDAC1-GFP

$\square$ AAV-GFP

Figure 2. Overexpression of HDAC1 in the adult hippocampus. $A$, Experimental design. $B$, Quantitative real time PCR showed a sixfold increase of Hdac1 mRNA in the AVV-HDAC1-GFP-injected mice $14 \mathrm{~d}$ after injection $\left(n=3 /\right.$ group; ${ }^{* * *} p<0.0001$ ). C, The expression of other class I HDACs was unchanged in AAV-HDAC1-GFP-injected mice when analyzed $14 \mathrm{~d}$ after injection. $\boldsymbol{D}$, Immunoblot analysis was performed $14 \mathrm{~d}$ after injection. When compared with endogenous HDAC1 levels, AAV-HDAC1-GFP-injected mice displayed a twofold increased HDAC1 levels ( $n=4 / \mathrm{group})$. $\boldsymbol{E}$, Confocal imaging of hippocampal sections confirmed that nuclear HDAC1-GFP was detectable 14 but not $6 \mathrm{~d}$ after injection in AAV-HDAC1-GFP-treated mice $(n=4 / \mathrm{group})$. Scale bar, $200 \mu \mathrm{m}$. At $14 \mathrm{~d}$ : Left panel displays colocalization of HDAC1 and HDAC1-GFP in the adult dorsal hippocampus. Middle panel displays corresponding high-magnification images. Right panel displays the ventral hippocampus where no HDAC1-GFP expression was detected. Scale bar, $50 \mu \mathrm{m}$. $\boldsymbol{F}$, The same lysates as described in $\boldsymbol{D}$ were used to analyze protein levels of HDAC2, HDAC3 and HDAC8. No difference was observed among groups. Protein $(30 \mu \mathrm{g})$ was used for immunoblot analysis. Error bars indicate SEM.

HDAC-GFP and AAV-GFP particles were injected into the dorsal hippocampus of mice and the corresponding expression was analyzed either 6 or $14 \mathrm{~d}$ later (Fig. $2 A$ ). qPCR analysis displayed a significant increase of Hdacl mRNA $14 \mathrm{~d}$ after injection (Fig. $2 B)$. Overexpression of HDAC1 did not alter levels of other class I HDACs (Fig. 2C). Administration of AAV-HDAC1-GFP resulted in a twofold increase of hippocampal HDAC1 protein when measured 2 weeks after injection (Fig. 2D). HDAC1-GFP was localized to neuronal nuclei within the dorsal hippocampus (Fig. 2E), whereas ventral hippocampus was not affected by AAV-HDAC1-GFP injection in the dorsal hippocampus. Other class I HDACs were not affected by HDAC1 overexpression (Fig. $2 F$ ). Thus, we concluded that our virus expression system can be used to achieve spatially restricted HDAC1 overexpression in the adult hippocampus of mice.

\section{Cognitive function in AAV-HDAC1-GFP-injected mice}

To investigate the impact of elevated hippocampal HDAC1 levels on cognitive function, we injected mice with AAV-HDAC1-GFP or AAV-GFP into the dorsal hippocampus. Two weeks later, we subjected these groups to behavior paradigms that allowed us to assess cognitive function relevant for neuropsychiatric diseases. Activity in the open field test was similar among groups, indicating that explorative behavior in a novel context was unaffected by elevated hippocampal HDAC1 levels (Fig. 3A). In addition, the time spent in the center of the open field, an indicator of basal anxiety, was similar among groups (Fig. $3 B$ ). When the same mice were subjected to the Porsolt forced swim test, a commonly used paradigm to test depressive-like behavior in rodents, no difference was observed (Fig. 3C). An additional group of mice was used to analyze working memory using the cross-maze (Fig. 
A

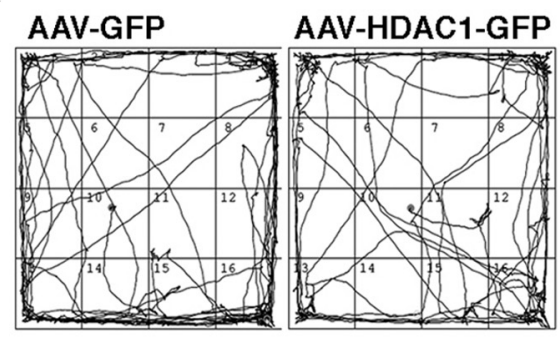

B

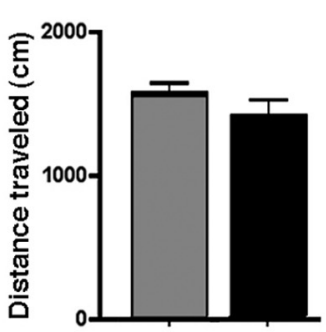

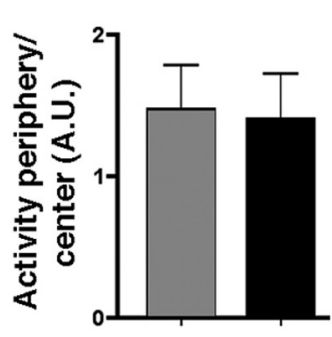

C

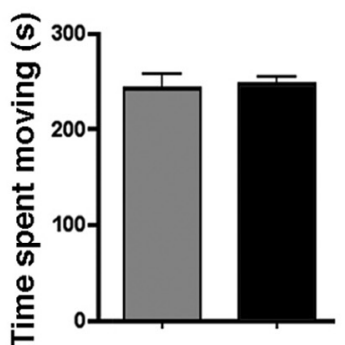

D

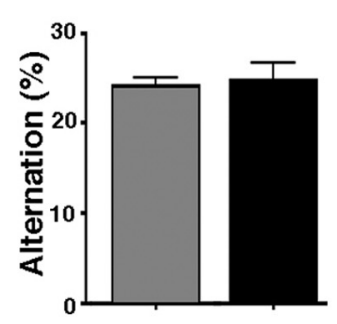

E

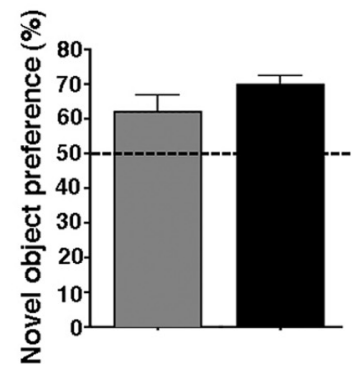

$F$

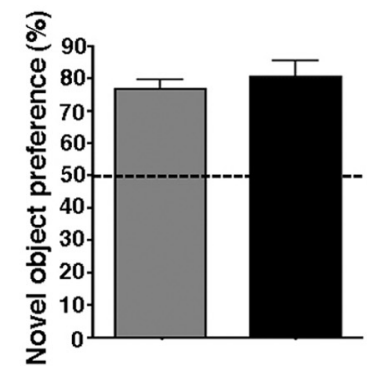

G

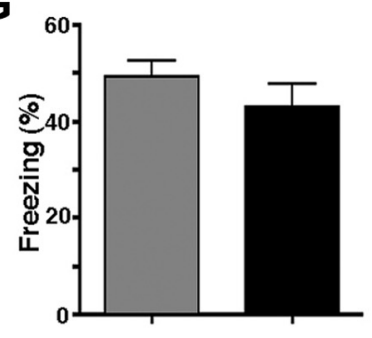

H

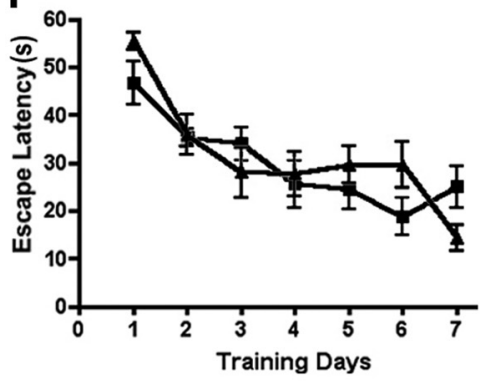

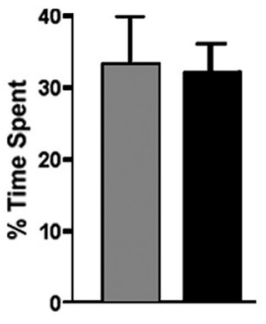

$\square$ AAV-GFP
I

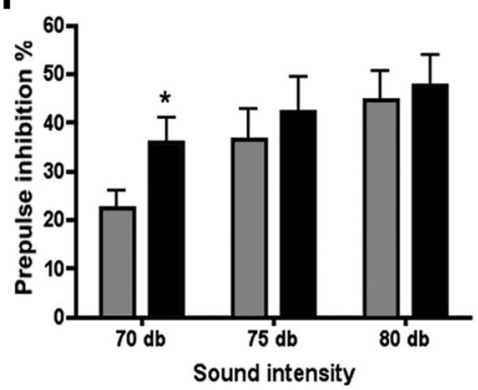

J

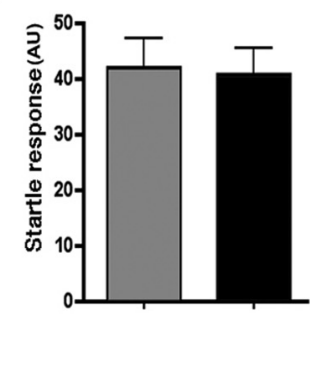

Figure 3. Cognitive function in AAV-HDAC1-GFP-treated mice. $\boldsymbol{A}$, Left, Representative path of mice in a 5 min open field exposure. Right, Distance traveled during 5 min open field exposure. $\boldsymbol{B}$, The ratio of time spent in the periphery vs the center of the open field was similar among groups. C, Depressive-like behavior was analyzed in the Porsolt forced swim test. No significant difference among groups was observed. $\boldsymbol{D}$, Working memory as assessed by the cross-maze test was not affected in AAV-HDAC1-GFP-injected mice. $\boldsymbol{E}$, Short-term memory (5 min) in the novel object recognition test was similar among groups. Dashed line indicates chance level. $\boldsymbol{F}$, Long-term memory $(24 \mathrm{~h})$ was analyzed in the novel object recognition test. No difference among groups was observed. Dashed line indicates chance level. G, Associative memory was analyzed using contextual fear conditioning. Freezing was similar among groups. $\boldsymbol{H}$, Left, The escape latency during water maze training was similar among groups. Right, No difference among groups was observed in the probe test performed $24 \mathrm{~h}$ after the last training session. I, Prepulse inhibition of the startle response was significantly increased at low intensities $(70 \mathrm{~dB})$ in AAV-HDAC1-GFP-treated mice ${ }^{*} p<0.05$ vs AAV-GFP). J, Startle response was not affected in AAV-HDAC1-GFP-injected animals. $n=9-10 /$ group. Error bars indicate SEM.

$3 D$ ) and the novel object recognition test (Fig. 3E); again, no difference among the AAV-HDAC1-GFP and AVV-GFP groups was observed. The consolidation of long-term memories was analyzed via three different behavior tests. No differences among groups were observed in the novel object recognition (Fig. $3 F$ ), the contextual fear conditioning (Fig. $3 G$ ), or the Morris water maze paradigms (Fig. $3 H$ ), which all depend on proper function of the hippocampus. We used additional mice to investigate PPI of the startle response, a specific form of sensory motor gating that is impaired in mouse models for schizophrenia (SZ) and in SZ patients (Amann et al., 2010). Interestingly, PPI measured at moderate prepulse intensities was significantly increased in AAVHDAC1-GFP-injected mice compared with the AAV-GFP group (Fig. 3I), while no significant difference in the startle response itself was observed between groups (Fig. $3 \mathrm{~J}$ ). Immunohistochemical analysis of the NeuN and MAP2 proteins, two well established markers for neuronal integrity (Fischer et al., 2007), revealed no obvious differences among groups (data not shown).
In summary, our data show that virus-mediated neuronal overexpression of HDAC1-GFP in the dorsal hippocampus of adult mice did not lead to an obvious detrimental behavioral phenotype.

Overexpression of HDAC1 enhances fear extinction learning Recent data suggested that differential regulation of hippocampal histone acetylation not only is required for the acquisition of novel memory traces but may also play an important role for the extinction of fear memories (Bredy et al., 2007; Lattal et al., 2007). The role of specific HDACs in fear extinction has so far not been investigated. Fear extinction is a specific form of learning and represents an important mechanism to inhibit excess fear, which is typically achieved via repeated reexposure to the fear-eliciting stimulus in the absence of the aversive event (Bouton, 2004; Myers and Davis, 2007). In the laboratory, hippocampus-dependent fear extinction can be studied in rodents by using the contextual fear conditioning paradigm (Fischer and Tsai, 2008). Here, single 
A
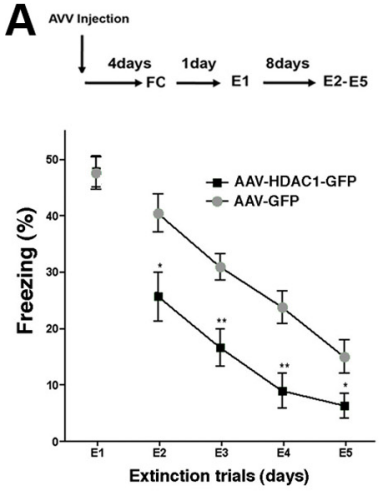

D

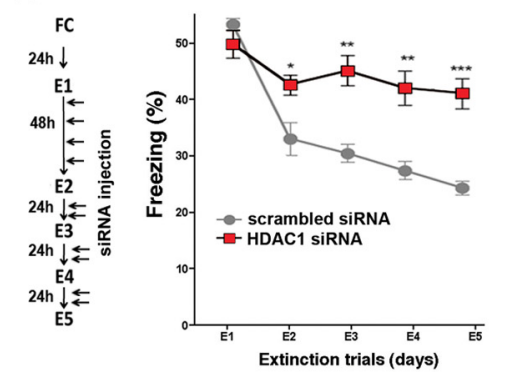

Figure 4. Hippocampal HDAC1 affects the extinction of fear memories. A, Top, Experimental design. Bottom, While AAVHDAC1-GFP and AAV-GFP-injected mice ( $n=10$ /group) show similar freezing behavior on E1, fear extinction learning was significantly enhanced in the AAV-HDAC1-GFP group $\left({ }^{*} p<0.05,{ }^{* *} p<0.01\right.$ for day comparison; repeated measurements $p=$ $0.001, F=12,78)$. $\boldsymbol{B}$, Top, Experimental design. Bottom, When compared with the vehicle group $(n=21)$, intrahippocampal injection of MS-275 $(n=21)$ immediately after each extinction trial impaired fear extinction $\left({ }^{*} p<0.05\right.$ for day comparison; contextual fear memories. Microcannulae were implanted into the hippocampus of mice $(n=7 /$ group). After recovery all animals were subjected to contextual fear conditioning. Immediately after the training mice were injected with the same concentration of MS-275 that was used for fear extinction experiments fear memory was analyzed $24 \mathrm{hlater}$. Notably, freezing behavior during the memory test was similar between MS-275 and vehicle-injected mice. $\boldsymbol{D}$, Left, Experimental design. Right, When compared with the control group that received a scrambled control RNA $(n=6)$, intrahippocampal injection of HDAC1 siRNA $(n=6)$ impaired fear extinction $\left({ }^{*} p<0.05,{ }^{* *} p<0.001\right.$ for day comparison; repeated measurements $\left.p=0.0001, F=21,89\right)$. $E$, HDAC1 siRNAtreated mice display significantly reduced hippocampal levels of Hdac1 mRNA and HDAC1 protein, measured via qPCR and quantitative immunoblot respectively ( $n=5 /$ group $)^{* *} p<0.001$ vs scrambled RNA). Error bars indicate SEM. repeated measurements $p=0.0038, F=9,435)$. $C$, Intrahippocampal injection of MS-275 does not affect the consolidation of

ing that HDAC1 regulates the extinction of contextual fear memories.

\section{Inhibition of HDAC1 impairs fear extinction}

To further investigate the involvement of hippocampal HDAC1 during fear extinction, microcannulae were implanted into the hippocampus of mice. After recovering from surgery, mice were subjected to fear conditioning followed by extinction training. Immediately after each extinction trial, mice were injected with MS275, an HDAC inhibitor that inhibits HDAC1 in nanomolar concentrations, has a 100-fold higher $\mathrm{EC}_{50}$ toward HDAC2/HDAC3, and has no activity toward the other HDACs ( $\mathrm{Hu}$ et al., 2003; Khan et al., 2008). Mice that received vehicle solution served as a control group (Fig. 4B). While freezing behavior within the vehicle group declined throughout extinction training ( $p<0.005$ for E1 vs E6), MS-275-injected mice showed elevated freezing throughout extinction trials (Fig. $4 B ; p=0.0038, F=9,435 ;{ }^{*} p<0.05 \mathrm{MS}$ 275 vs vehicle on days). Notably, the same dose of MS-275 did not affect the acquisition of fear memories (Fig. 4C). To further confirm that inhibition of HDAC1 affects fear extinction, we used a siRNA approach (Zovoilis, 2011) to knock down hippocampal HDAC1 using a validated siRNA targeting HDAC1 (Liu et al., 2010) to affect hippocampal HDAC1 levels. Mice were fear conditioned and subjected to E1 $24 \mathrm{~h}$ later. Within the next $48 \mathrm{~h}$, mice were injected with HDAC1 siRNA for 4 times every $12 \mathrm{~h}$ before exposure to E2. Injection of siRNA was continued after exposure of rodents to a novel context followed by an electric footshock elicits the acquisition of hippocampus-dependent fear memory that is measured as the amount of aversive freezing behavior. During extinction training, animals are reexposed to the conditioned context on subsequent days without receiving the footshock again (extinction trial, E), which eventually results in the decline of the freezing response (Fischer et al., 2004; Sananbenesi et al., 2007; Fischer and Tsai, 2008; Tronson et al., 2009). Thus, we decided to test whether elevated HDAC1 levels would affect contextual fear extinction. Our virus-mediated approach allowed us to design an experiment in which HDAC1-GFP is overexpressed specifically during fear extinction without affecting the process of memory consolidation. To this end, mice were subjected to fear conditioning $4 \mathrm{~d}$ after AAV-HDAC1-GFP injection, followed by exposure to E1 $24 \mathrm{~h}$ later. A control group was injected with AAV-GFP. As such, the acquisition of fear memories occurred in the absence of HDAC1 overexpression (Fig. 4A; see also Fig. 2). All groups showed similar freezing levels during E1 (Fig. 4B). After another $8 \mathrm{~d}$, when HDAC1-GFP was strongly expressed (Fig. 2), mice were subjected to extinction training on subsequent days (E2-E5) (Fig. $4 B$ ). Notably, fear extinction was significantly facilitated in the AAV-HDAC1-GFP group (Fig. $4 B ;{ }^{\star} p<0.05,{ }^{\star *} p<0.01$ for day comparison; repeated measurements $p=0.001, F=12,78$ ), suggest- exposure to extinction trials 3-5, which were performed on consecutive days (Fig. $4 D$ ). Mice that received a scrambled control RNA served as control group. Fear extinction was significantly impaired in HDAC1 siRNA-treated mice (Fig. 4D), which correlated with the reduction of hippocampal Hdacl mRNA and HDAC1 protein levels in siRNA-treated mice (Fig. $4 E$ ). In conclusion, our results show that virus-mediated overexpression of HDAC1 enhances, while intrahippocampal injection of MS-275 and hippocampal knockdown of HDAC1 impairs, fear extinction. These findings suggest a specific role of HDAC1 for the extinction of contextual fear memories.

\section{HDAC1-mediated transcriptional repression during fear extinction learning}

Taking into account that HDAC1 activity is associated with genesilencing (Gregoretti et al., 2004; Fischer et al., 2010), we hypothesized that HDAC1 may affect fear extinction via mechanisms that involve transcriptional repression. HDAC1 activity has been implicated in the regulation of the expression of $c$-Fos (Yang et al., 2001; Usenko et al., 2003; Renthal et al., 2008), an immediate early gene that is transiently upregulated after contextual fear conditioning (Radulovic et al., 1998; Peleg et al., 2010) and whose protein levels are reduced after extinction training (Tronson et 
A

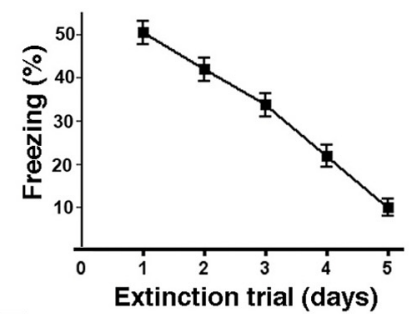

E

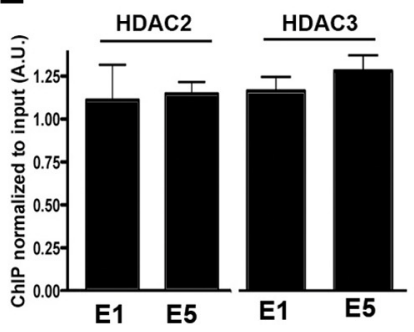

B

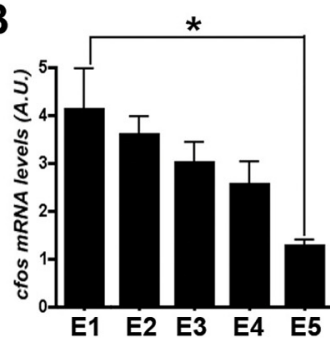

F

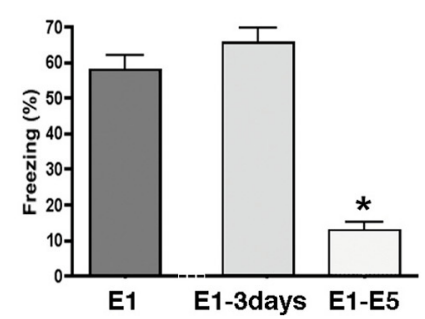

C

G
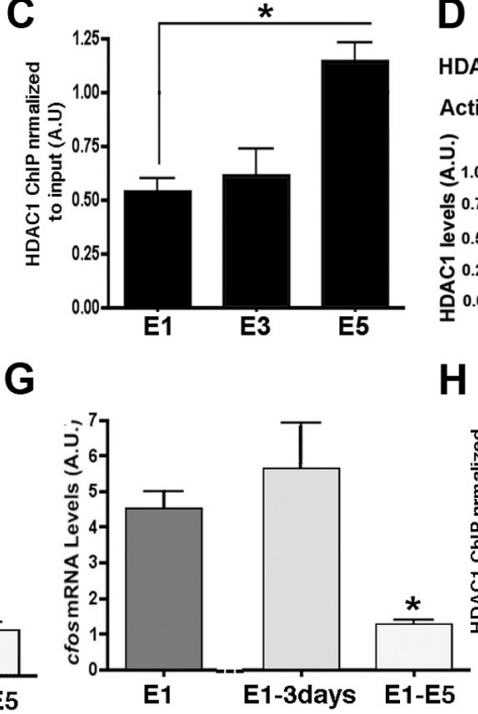
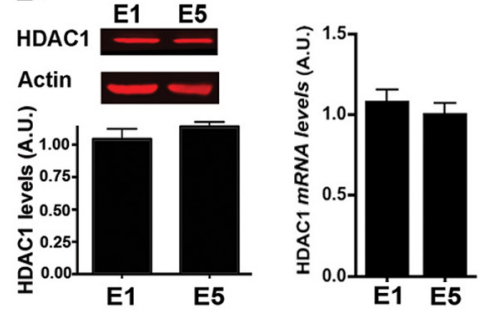

H

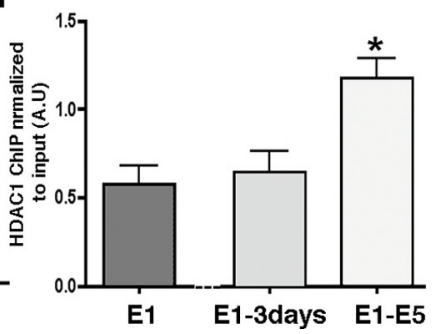

Figure 5. Fear extinction-dependent recruitment of HDAC1 to the c-Fos promoter. A, Fear extinction in the mice $(n=45)$ used for molecular analysis in B-E $(n=5 /$ group). $B, c-F o s$ expression was analyzed via qPCR in hippocampal tissue isolated $1 \mathrm{~h}$ after exposure to extinction trials. The data are normalized to tissue obtained from a naive control group. C, HDAC1 ChIP was performed from hippocampal tissue $1 \mathrm{~h}$ after exposure to E1, E3, and E5. Note that the downregulation of c-Fos correlates with recruitment of HDAC1 to the c-Fos promoter. D, Normalized hippocampal HDAC1 protein levels (left, images show representative immunoblot analysis, $30 \mu \mathrm{g}$ of hippocampal protein was loaded per lane) and mRNA levels (right) were similar among groups when compared $1 \mathrm{~h}$ after E1 and E5 exposure. $E$, ChIP analysis of the c-Fos promoter was performed for HDAC2 and HDAC3 after E1 and E5. No significant difference among groups was observed. $F$, Freezing behavior in the E1-3 d group is significantly higher when compared with the E1-E5 group ( $n=5 /$ group). $G$, c -Fos expression was measured $1 \mathrm{~h}$ after extinction trials. c-Fos levels were significantly higher in the E1-3 d group when compared with E1-E5 group ( $n=5 /$ group). $\boldsymbol{H}$, HDAC1 ChIP was performed from hippocampal tissue $1 \mathrm{~h}$ after exposure to extinction trial in the E1, E1-3 d, and E1-E5 groups ( $n=$ 5/group). Note that the increased c-Fos expression in the E1-3 d group correlates with reduced HDAC1 level at the c-Fos promoter. Error bars indicate SEM.

al., 2009). Thus, we hypothesized that monitoring transcriptional regulation of c-Fos during fear extinction could be a suitable tool to explore the mechanisms by which $\mathrm{HDAC} 1$ affects the extinction of fear memories.

To test this possibility, mice were subjected to our fear extinction paradigm. All mice displayed high freezing behavior on E1 (Fig. 5A). The freezing response progressively declined throughout extinction training (Fig. 5A). From the same group of animals we randomly selected mice to isolate hippocampal tissue $1 \mathrm{~h}$ after each extinction trial. All data were normalized to naive animals that did not undergo fear extinction. Robust $c$-Fos expression was observed after exposure to E1 but progressively declined throughout fear extinction training (Fig. 5B). Having established that $c$-Fos is downregulated during the course of fear extinction training, we used ChIP assays to analyze HDAC1 protein binding at the $c$-Fos promoter region during extinction. Mice were subjected to fear extinction training and hippocampal tissue was isolated $1 \mathrm{~h}$ after exposure to E1, E3, or E5. Interestingly, ChIP analysis shows that HDAC1 levels at the $c$-fos promoter were significantly increased $1 \mathrm{~h}$ after E5 when compared with E1 or E3 (Fig. $5 C$ ). This effect was not due to altered HDAC1 protein or mRNA levels, since no difference was observed when comparing hippocampal lysates prepared $1 \mathrm{~h}$ after E1 and E5 (Fig. $5 D$ ). These data indicate that recruitment of HDAC1 may mediate the repression of $c$-Fos during fear extinction. No difference among E1 and E5 was observed for the class I HDACs HDAC2 and HDAC3 (Fig. 5E).

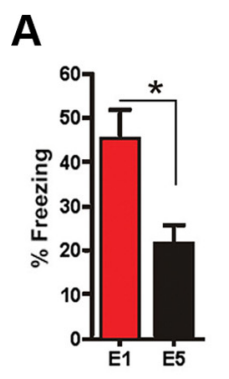

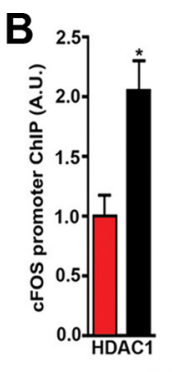
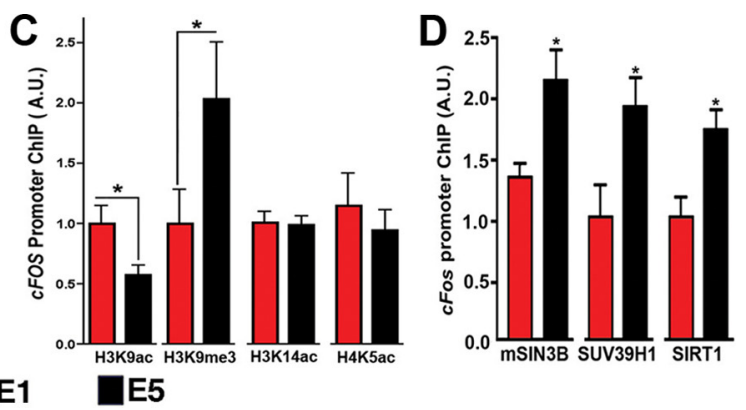

Figure 6. Chromatin remodeling at the c-Fos promoter during fear extinction. $A$, Mice $(n=10)$ were subjected to fear extinction training. Hippocampal tissue was isolated and prepared for ChIP analysis either $1 \mathrm{~h}$ after $\mathrm{E} 1$ or $1 \mathrm{~h}$ after $\mathrm{E}$ exposure. $\left({ }^{*} p<0.05\right.$ C. ChIP analysis revealed decreased $\mathrm{H} 3 \mathrm{~K} 9$ acetylation and increased $\mathrm{H} 3 \mathrm{~K} 9$ trimethylation at the $c$-Fos promoter upon $\mathrm{E} 5$ exposure $\left({ }^{*} p<0.05\right.$ vs E1). D, Increased mSIN3B, SUV39H1 and SIRT1 levels were detected at the $c-$ Fos promoter upon E5 exposure ( $p<$ 0.05 vs E1). Error bars indicate SEM.

However, the possibility remains that the observed decrease of $c$-Fos expression and HDAC1 recruitment to the corresponding promoter simply reflects the passing of time and thus would not be suitable to study the specific actions of HDAC1 during fear extinction training.

To test this possibility, mice were subjected to contextual fear conditioning followed by E1 exposure. Subsequently, animals were divided into two groups. One group of mice was subjected to extinction training on 4 consecutive days (E1-E5 group), while the other group of mice was exposed to E2 $3 \mathrm{~d}$ after E1 exposure (E1-3 d group). Notably, in contrast to the E1-E5 group, freezing behavior in the E1-3 d group did not decline (Fig. $5 F$ ). These data confirm that in our experimental setting, the extinction of fear memories critically depends on the daily exposure to extinction training. We used the same experimental setting to analyze hippocampal $c$-Fos expression by qPCR $1 \mathrm{~h}$ after exposure to E1, E2 
A B

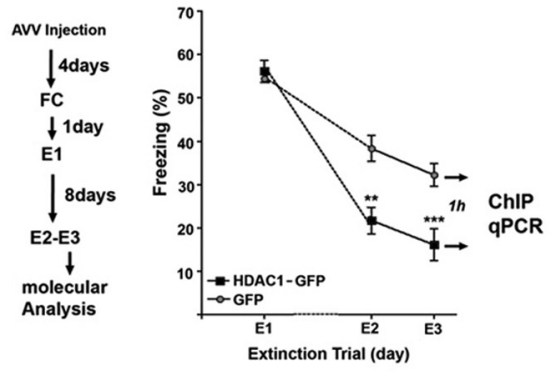

C

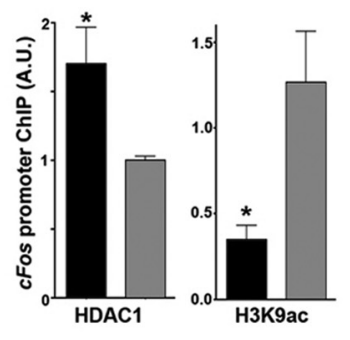

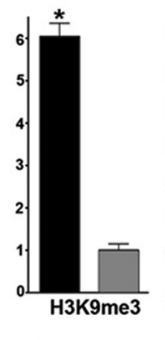

AAV-HDAC1-GFP $\square$ AAV-GFP
D

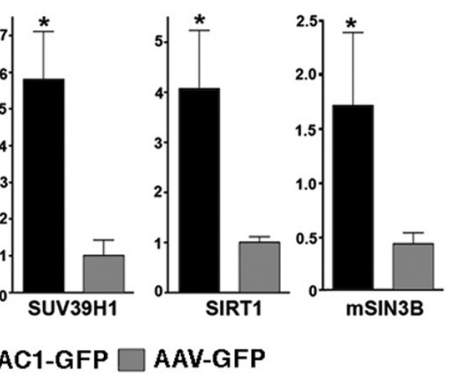

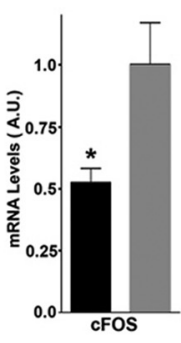

Figure 7. $\mathrm{HDAC1}$ regulates $\mathrm{H} 3 \mathrm{~K} 9$ modifications and c-Fos expression during fear extinction. $\boldsymbol{A}$, Experimental design for $\boldsymbol{B}-\boldsymbol{D}$. $\boldsymbol{B}$, Freezing behavior during $\mathrm{E} 1$ was indistinguishable between AAV-HDAC1-GFP and AAV-GFP-injected mice ( $n=10$ /group). However, AAV-HDAC1-GFP-injected mice displayed significantly reduced fear extinction upon E2 and E3 exposure indicating facilitated fear extinction ${ }^{* *} p<0.01,{ }^{* * *} p<0.0001$ vs AAV-GFP). Hippocampus was isolated and prepared for molecular analysis $1 \mathrm{~h}$ after E3 exposure ( $n=10 /$ group). C, ChIP analysis of the c-Fos promoter in AAV-HDAC1-GFP and AAV-GFP-injected mice. ${ }^{*} p<0.05$ vs AAV-GFP). D, qPCR shows decreased hippocampal c-Fos levels in the AAV-HDAC1-GFP group. ${ }^{*} p<0.05$ vs AAV-GFP. Error bars indicate SEM.

in the E1-3 d group and E5 in the E1-E5 group. While c-Fos expression decreased in the E1-E5 group when compared with E1, no such effect was observed in the E1-3 d group (Fig. 5G). These data demonstrate that downregulation of $c$-Fos during fear extinction training reflects an active process that is likely to involve transcriptional repression. Next, we used the same experimental setting to analyze HDAC1 levels at the $c$-Fos promoter. When compared with E1 exposure, HDAC1 levels at the $c$-Fos promoter were significantly increased $1 \mathrm{~h}$ after E5 in the E1-E5 group. In contrast, the levels of HDAC1 at the $c$-Fos promoter were indistinguishable among the E1 group and the E1-3 d group (Fig. 5H).

In conclusion, these data show that the analysis of $c$-Fos expression $1 \mathrm{~h}$ after E1 compared with E5 can serve as a model to investigate the molecular mechanisms by which HDAC1 affects gene expression during fear extinction.

Thus, we used ChIP analysis to compare histone modifications at the $c$-Fos promoter $1 \mathrm{~h}$ after E1 and E5 exposure. Mice were subjected to fear extinction training and hippocampal lysates were prepared $1 \mathrm{~h}$ after E1 and E5 exposure (Fig. 6A). In line with our previous observation, HDAC1 levels at the $c$-Fos promoter were higher in the E5 when compared with the E1 group (Fig. 6B). The same samples were used to analyze the levels of histone modifications via ChIP analysis. $\mathrm{H} 3 \mathrm{~K} 9$ acetylation, a histone modification linked to active gene expression and HDAC1 activity (Fischer et al., 2010; Peleg et al., 2010), was significantly decreased at the $c$-Fos promoter in the E5 group when compared with the E1 group (Fig. 6C). Conversely, the levels of H3K9 trimethylation, a mark for inactive chromatin, were elevated (Fig. $6 C)$. Other histone modifications such as $\mathrm{H} 3 \mathrm{~K} 14$ or $\mathrm{H} 4 \mathrm{~K} 5$ acetylation were not altered among groups (Fig. 6C). These data suggest that HDAC1 is recruited to the $c$-Fos promoter during fear extinction, where it contributes to the deacetylation of $\mathrm{H} 3 \mathrm{~K} 9$, which led subsequently to $\mathrm{H} 3 \mathrm{~K} 9$ trimethylation. One of the key enzymes that mediates $\mathrm{H} 3 \mathrm{~K} 9$ methylation is the histone methyltransferase suppressor of variegation 3-9 homolog (SUV39H1) (Krauss, 2008), which is activated via deacetylation by silent mating type information regulation 2 homolog (SIRT1) (Vaquero et al., 2007) and regulates heterochromatin formation resulting in gene-silencing (Schotta et al., 2003). Notably, SUV39H1 is known to interact with HDAC1 (Vaute et al., 2002) and can act in concert with the HDAC1/mSIN3B corepressor complex (Jepsen and Rosenfeld, 2002; Bandyopadhyay et al., 2007; David et al., 2008; Renthal et al., 2008) to regulate gene-silencing.
Therefore, we decided to investigate the levels of mSIN3B, SUV39H1, and SIRT1 at the $c$-Fos promoters during fear extinction via ChIP analysis. Similar to our findings for HDAC1, we observed a significant upregulation of $\mathrm{mSIN} 3 \mathrm{~B}, \mathrm{SUV} 39 \mathrm{H} 1$, and SIRT1 levels at the $c$-Fos promoter $1 \mathrm{~h}$ after E5 exposure when compared with E1 (Fig. 6D).

In conclusion, these data suggest that HDAC1 deacetylates $\mathrm{H} 3 \mathrm{~K} 9$ at the $c$-Fos promoter during fear extinction, which allows for $\mathrm{H} 3 \mathrm{~K} 9$ trimethylation, leading to repression of the $c$-Fos gene.

To test directly whether HDAC1 activity regulates $\mathrm{H} 3 \mathrm{~K} 9$ modification at the $c$-Fos promoter and $c$-Fos expression during fear extinction, we assessed chromatin modifications and $c$-Fos gene expression during extinction training in mice that either overexpress HDAC1-GFP or received intrahippocampal injection of the HDAC inhibitor MS-275.

First we used the virus expression system to overexpress HDAC1. Mice were injected with AAV-HDAC1-GFP particles and subjected to fear conditioning $4 \mathrm{~d}$ later. Mice injected with AAV-GFP served as the control group (Fig. 7A). All mice showed robust, but indistinguishable freezing behavior during a memory test performed $24 \mathrm{~h}$ later (Fig. $7 B$ ). Eight days later, when AAVHDAC1-GFP was strongly expressed, mice were subjected to fear extinction training (Fig. $7 A, B$ ). Hippocampal tissue was isolated $1 \mathrm{~h}$ after exposure to E3. We chose the E3 rather than the E5 time point, since freezing behavior was already significantly reduced in the HDAC1-AAV-GFP mice when compared with the AAV-GFP group (Fig. $7 B$ ). Notably, H3K9 acetylation at the $c$-Fos promoter was significantly reduced in AAV-HDAC1-GFP-injected mice when compared with the GFP-control group (Fig. 7C). Conversely, $\mathrm{H} 3 \mathrm{~K} 9 \mathrm{me} 3$ levels were strongly increased (Fig. 7C). In line with these data, we detected increased levels of HDAC1, mSin $3 b$, SUV39H1, and SIRT at the $c$-Fos promoter in the AAV-HDAC1GFP group (Fig. 7C). Moreover $c$-Fos gene expression was significantly lower in AVV-HDAC1-GFP-injected mice when compared with the AAV-GFP group (Fig. 7D). These data further confirm that our HDAC1-GFP fusion protein is functional in vivo and suggests that $\mathrm{HDAC} 1$ regulates $\mathrm{H} 3 \mathrm{~K} 9$ acetylation at the $c$-Fos promoter during fear extinction.

In the converse experiment, microcannulae were implanted into the hippocampus of mice. After recovery, animals were subjected to our fear extinction paradigm and injected with MS-275 or vehicle immediately after each extinction trial (Fig. $8 \mathrm{~A}$ ). In line with our previous observation, MS-275-injected mice displayed impaired fear extinction when compared with the vehicle group 
(Fig. 8A). Hippocampal tissue was isolated $1 \mathrm{~h}$ after E5 from vehicle- and MS275-injected mice and used for qPCR analysis. Using ChIP analysis, we observed higher levels of H3K9 acetylation and decreased $\mathrm{H} 3 \mathrm{~K} 9$ trimethylation levels in the MS-275 group when compared with vehicle-treated mice (Fig. $8 B$ ). Those changes in $\mathrm{H} 3$ modification correlated with increased hippocampal c-Fos mRNA levels in MS-275-injected mice (Fig. 8C). Similar results were obtained when hippocampal HDAC1 level were reduced via administration of HDAC1 siRNA. Hippocampal tissue from the mice used in the behavior experiment shown in Figure $4 D$ and killed $1 \mathrm{~h}$ after E5 were used for molecular analysis. As shown in Figure $4 E$, HDAC1 siRNA-treated mice display significantly reduced HDAC1 protein levels. Consistently, ChIP analysis revealed less HDAC1 at the c-Fos promoter in HDAC1 siRNA-treated mice when compared with animals injected with the scrambled control RNA (Fig. 8D). In line with these data, ChIP analysis revealed that HDAC1 siRNA-treated mice show increased levels of $\mathrm{H} 3 \mathrm{~K} 9$ acetylation and decreased $\mathrm{H} 3 \mathrm{~K} 9 \mathrm{me} 3$ at the c-Fos promoter (Fig. $8 \mathrm{E}$ ), which correlated with increased expression of the $c$-Fos gene (Fig. $8 F$ ). In conclusion, these data suggest that HDAC1-dependent epigenetic gene expression contributes to the extinction of contextual fear memories.

\section{Discussion}

\section{Overexpression of hippocampal HDAC1}

To further understand the role of elevated HDAC1 levels that have been observed in various brain diseases (Benes et al., 2007; Sharma et al., 2008; Quinti et al., 2010; Wang et al., 2011), we generated AAVHDAC1-GFP particles that resulted in a twofold increase of neuronal and nuclear HDAC1 levels when injected into the dorsal hippocampus of mice, while other class I HDACs were unaffected. Whether HDAC1 regulates class II HDACs remains to be investigated. We choose the hippocampus since this brain region is essential for memory function, which is impaired in various neuropsychiatric diseases. Interestingly, we found that explorative and depressive-like behavior was not affected by virus-mediated overexpression of HDAC1. We also did not observe any effect on working and short-term memory in the cross-maze and novel object recognition paradigms. Moreover, hippocampus-dependent long-term memory that was measured using three different tests did not reveal any changes in AAV-HDAC1-GFP-injected mice when compared with the AAV-GFP control. This finding is in line with previous data showing that neuronal overexpression of HDAC1 throughout development does not affect memory consolidation in the fear conditioning and water maze paradigm in adult mice (Guan et al., 2009). The fact that increased hippocampal HDAC1 levels did not affect behavior in any of the cognitive tests analyzed was nevertheless surprising, since we had hypothesized that acute overexpression of HDAC1 in the adult hippocampus may more closely resemble the situation observed in patients, especially since acute overexpression of HDAC1 did not affect the expression of other hippocampal class I HDACs. Interestingly, a small but significant difference
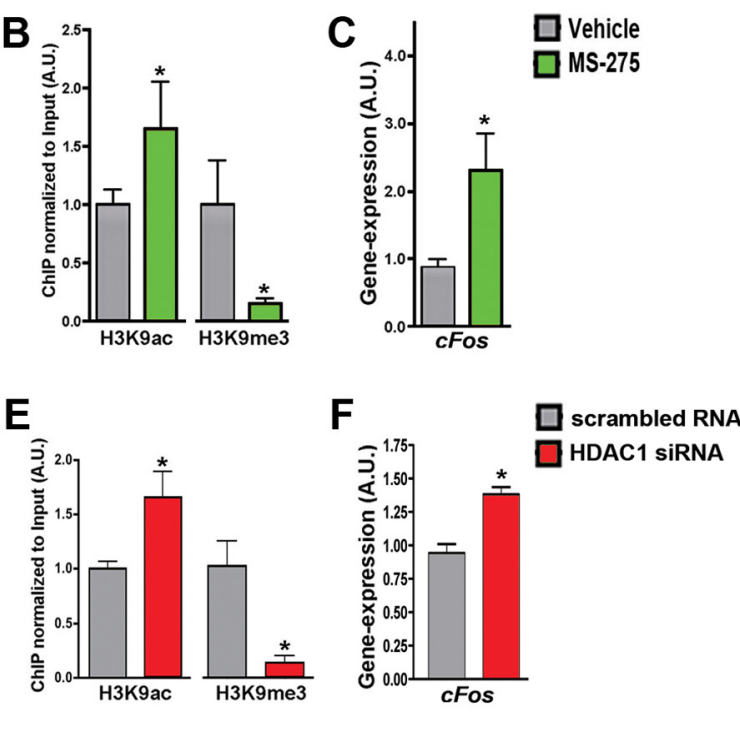

Figure 8. Inhibition of HDAC1 activity during fear extinction increases H3K9ac and c-Fos expression. $\boldsymbol{A}$, Mice that were injected in HDAC1 levels $(\boldsymbol{D})$, increased H3K9 acetylation and decreased $\mathrm{H} 4 \mathrm{~K} 9$ methylation $(\boldsymbol{E})$ at the CFos promoter while cFos expression was increased $(\boldsymbol{F})$ when compared with scrambled RNA-treated mice $\left(n=4,{ }^{*} p<0.05\right)$. Error bars indicate SEM.

in the PPI of the startle response was observed. PPI, which is often impaired in schizophrenia patients and in animal models for schizophrenia-like behavior, was increased in AAV-HDAC1GFP-treated mice at $70 \mathrm{~dB}$ sound intensity. Overexpression of HDAC1 did not lead to any obvious morphological changes within the hippocampus. In conclusion, our data show that elevation of HDAC1 protein levels in the mouse hippocampal neurons did not lead to obvious detrimental phenotypes.

\section{Hippocampal HDAC1 regulates fear extinction}

In our experimental setting, we were unable to detect changes in short- or long-term memory acquisition in response to HDAC1 overexpression, which does not rule out the possibility that under physiological conditions HDAC1 may serve a rather specific role in cognitive function. Thus, we decided to investigate fear extinction learning, a specific form of emotional memory that is also affected in patients suffering from schizophrenia (Holt et al., 2009). While fear is a physiological response to threatening stimuli, excessive fear is the basis of anxiety diseases, and therapeutic approaches often involve fear extinction learning (Bouton, 2004; Delamater, 2004; Myers and Davis, 2007; Fischer and Tsai, 2008). Recent studies implicated fear extinction with histone acetylation. It was shown that systemic or intrahippocampal administration of HDAC inhibitors such as sodium butyrate, valproate, or trichostatin A (TSA) facilitates fear extinction in mice (Bredy et al., 2007; Lattal et al., 2007; Bredy and Barad, 2008). A role for individual HDAC proteins during fear extinction has so far not been described. We observed that mice that overexpress HDAC1 in the hippocampus exhibit facilitated extinction of contextual fear memories. Conversely, intrahippocampal injection of MS275, a class I HDAC inhibitor with selectivity toward HDAC1 (Hu et al., 2003; Khan et al., 2008), inhibited the extinction of contextual fear in mice. Similar data were observed when HDAC1 levels were decreased using siRNA. The effect of MS-275 
was specific to fear extinction since single intrahippocampal injection of MS-275 immediately after fear conditioning did not affect freezing behavior during a memory test performed $24 \mathrm{~h}$ later. In conclusion, these data suggest that HDAC1 activity is required for fear extinction. That administration of the HDAC inhibitor TSA facilitates fear extinction (Lattal et al., 2007) could be explained by the fact that TSA is rather unselective and inhibits all HDAC proteins. Therefore, HDACs other than HDAC1 might act as negative regulators of fear extinction. Likely candidates would be HDAC2 (Guan et al., 2009) and HDAC3 (McQuown et al., 2011), which act as negative constraints of memory function. In contrast, the administration of TSA to neuronal cells was shown to increase the expression of HDACl (Ajamian et al., 2004), which provides another possible explanation why the panHDAC inhibitor TSA facilitates fear extinction. Future studies that specifically address the role of HDAC2-11 during fear extinction will be necessary to clarify this issue.

The finding that HDAC1 affects contextual fear extinction allowed us to use this experimental paradigm to investigate in more detail the molecular mechanisms by which HDAC1 modulates cognitive function.

\section{Transcriptional repression during fear extinction}

Since HDAC1 activity is generally linked to gene repression, we hypothesized that HDAC1-mediated gene silencing may play a role during the extinction of contextual fear memories. Previous data showed that hippocampal $c$-FOS levels are elevated after exposure to E1 but gradually decrease throughout extinction training (Tronson et al., 2009). In line with these data, we found that in our fear extinction paradigm, hippocampal expression of the $c$-Fos gene gradually declines throughout extinction training when measured $1 \mathrm{~h}$ after exposure to each extinction trial. We show that the repression of $c$-Fos is not simply due to the passing of time but is specific for extinction training. Therefore, we decided to monitor epigenetic changes at the $c$-Fos promoter to investigate a role of HDAC1 during fear extinction learning. We found that reduced $c$-Fos expression upon E5 exposure correlated with increased HDAC1 levels at the $c$-Fos promoter region. Increased HDAC1 promoter binding at the $c$-Fos gene was accompanied by decreased $\mathrm{H} 3 \mathrm{~K} 9$ acetylation, a chromatin mark that is generally associated with active gene expression (Kouzarides, 2007). Other histone modifications such as H3K14 or H4K5 acetylation were not affected. However, we observed that the fear extinction-dependent decrease of $\mathrm{H} 3 \mathrm{~K} 9$ acetylation at the $c$-Fos promoter was associated with elevated trimethylation of $\mathrm{H} 3 \mathrm{~K} 9$, a histone modification that marks inactive chromatin. These data indicate that during fear extinction, HDAC1 is recruited to the c-Fos promoter where it deacetylates $\mathrm{H} 3 \mathrm{~K}$ 9, leading to subsequent $\mathrm{H} 3 \mathrm{~K} 9$ trimethylation. A major H3K9 methyltransferase is SUV39H1, which is activated via deacetylation by SIRT1 (Murayama et al., 2008) and was shown to regulate neuronal H3K9 methylation in response to environmental stimuli (Renthal et al., 2008). Indeed, we found that those enzymes along with HDAC1 and the corepressor mSIN3B are recruited to the $c$-Fos promoter upon E5 exposure. As such, it is likely that HDAC1 initially deacetylates $\mathrm{H} 3 \mathrm{~K} 9$ and that subsequently, SUV39H1, which may be coactivated via SIRT1, promotes H3K9 methylation, leading to gene repression. Direct support for this interpretation stems from our finding that mice that overexpress hippocampal $\mathrm{HDAC} 1$ display reduced $\mathrm{H} 3 \mathrm{~K} 9 \mathrm{ac}$ and increased $\mathrm{H} 3 \mathrm{~K} 9 \mathrm{me} 3$ at the $c$-Fos promoter. Indeed, elevated HDAC1 levels at the $c$-Fos promoter also resulted in significantly increased levels of mSIN3B, SUV39H1, and SIRT1. As such, HDAC1 recruitment to the $c$-Fos
A

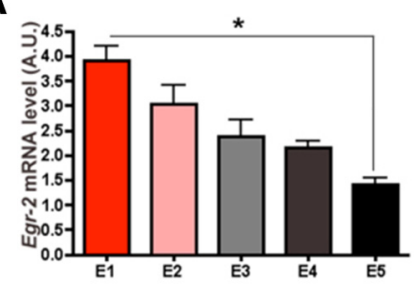

C
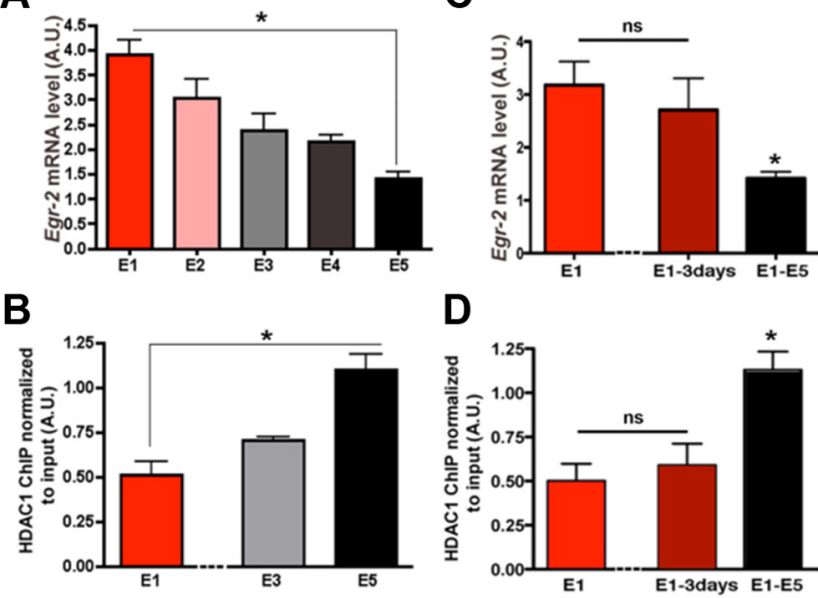

D

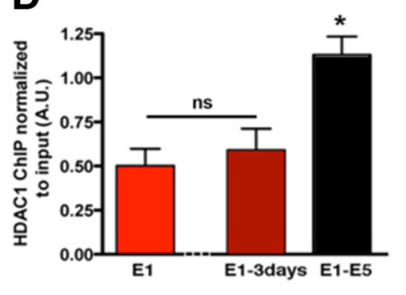

Figure 9. Fear extinction-dependent recruitment of HDAC1 to the Egr-2 promoter. Fear extinction training (see Fig. $5 A$ ) was performed in the mice $(n=40)$ that were used for the molecular analysis in $\boldsymbol{A}$ and $\boldsymbol{B}$. $\boldsymbol{A}$, Egr-2 expression was analyzed via qPCR in hippocampal tissue isolated $1 \mathrm{~h}$ after exposure to extinction trials. The data are normalized to tissue obtained from a naive control group. $\boldsymbol{B}, \mathrm{HDAC1} C \mathrm{Ch} P$ was performed from hippocampal tissue $1 \mathrm{~h}$ after exposure to E1, E3, and E5. Note that the downregulation of Egr-2 correlates with recruitment of HDAC1 to the Egr-2 promoter. C, We used the same samples described in Figure $5 D$ to analyze Egr-2 expression and HDAC1 recruitment to the Egr-2 promoter in the E1, the E1-3 d, and the E1-E5 group. We would like to reiterate that freezing behavior in the E1-3 d group was significantly higher when compared with the E1-E5 group. Egr-2 expression was measured $1 \mathrm{~h}$ after extinction trials. Egr-2 levels were significantly higher in the E1-3 d group when compared with E1-E5 group. ( ${ }^{*} p<0.05$ vs E1 and E1-3 d). D, HDAC1 ChIP was performed from hippocampal tissue $1 \mathrm{~h}$ after exposure to extinction trial in the E1, E1-3 d, and E1-E5 groups. Note that the increased Egr-2 expression in the E1-3 d group correlates with reduced HDAC1 level at the Egr-2 promoter. ${ }^{*} p<0.05$ vs E1 and E1-3 d. Error bars indicate SEM.

promoter seems to be sufficient to establish a chromatinsilencing complex that represses $c$-Fos expression during fear extinction. Consequently, inhibition of HDAC1 activity by MS-275 resulted in increased $\mathrm{H} 3 \mathrm{~K} 9$ acetylation and decreased $\mathrm{H} 3 \mathrm{~K} 9$ trimethylation at the $c$-Fos promoter which correlated with elevated c-Fos expression. A particular role for HDAC1 in the regulation of H3K9 is supported by recent studies. To this end, intrahippocampal injection of MS-275 increased H3K9 but not H4K12 acetylation (Peleg et al., 2010). Similarly, systemic administration of MS-275 to rats increased hippocampal $\mathrm{H} 3$ but not $\mathrm{H} 4$ acetylation (Simonini et al., 2006). Moreover, upon ethanol withdrawal, regulation of the nmda receptor subunit $2 b(n r 2 b)$ gene has been linked to changes in $\mathrm{H} 3 \mathrm{~K} 9$ acetylation involving $\mathrm{HDAC} 1$ activity and subsequent $\mathrm{H} 3 \mathrm{~K} 9$ methylation mediated via SUV39H1 (Qiang et al., 2011). A similar effect was seen in the zebrafish while knockdown of $\mathrm{Hdacl}$ eventually led to an upregulation of H3K9 methylation (Harrison et al., 2011).

In conclusion, our data suggest a scenario in which successful fear extinction requires $\mathrm{HDAC} 1$ activity to repress the activation of $c$-Fos via decreased $H 3 \mathrm{~K} 9$ acetylation. This allows subsequent $\mathrm{H} 3 \mathrm{~K} 9$ trimethylation leading to an inactive chromatin state. A similar role of HDAC1-mediated c-Fos expression has been observed in the striatum in response to chronic amphetamine exposure. Here amphetamine treatment recruited HDAC1 to the c-Fos promoter where it initiated gene-silencing via deacetylation of $\mathrm{H} 3$ that subsequently led to increased H3K9 dimethylation (Renthal et al., 2008).

It is important to note that we used c-Fos expression as a molecular tool to elucidate the mechanism by which HDAC1 affects fear extinction learning. It is likely that $\mathrm{HDAC} 1$ may reg- 
ulate the repression of immediate early genes during the course of extinction learning. In a recent study we performed an unbiased gene array to identify hippocampal genes that are differentially regulated during fear extinction. In line with the data presented in this study, we observed decreased c-Fos expression during extinction training (Agis-Balboa et al., 2011). A similar pattern was observed for another immediate early gene, early growth response 2 (Egr-2) (Agis-Balboa et al., 2011). Interestingly, we found that similar to $c$-Fos, Egr-2 expression is regulated during fear extinction training in an HDAC1-dependent manner that involved decreased $H 3 \mathrm{~K} 9$ acetylation and increased $\mathrm{H} 3 \mathrm{~K} 9$ trimethylation at the Egr-2 promoter (Fig. 9). Interestingly, levels of HDAC2, another class I HDAC that acts often in concert with HDAC1, did not change during the course of fear extinction at the c-Fos and Egr-2 promoter (data not shown). While these data suggest that during fear extinction HDAC1 activity plays a specific role in gene repression, further experiments will be necessary to unravel the precise genetic network that is affected by HDAC1. Moreover, we cannot exclude that the effect of HDAC1 on fear extinction learning is in part due to the action of HDAC1 on non-histone proteins.

In summary, our data show that HDAC1 is critical for the extinction of contextual fear memories and may provide a novel therapeutic avenue to treat anxiety diseases.

\section{References}

Agis-Balboa RC, Arcos-Diaz D, Wittnam J, Govindarajan N, Blom K, Burkhardt S, Haladyniak U, Agbemenyah HY, Zovoilis A, Salinas-Riester G, Opitz L, Sananbenesi F, Fischer A (2011) A hippocampal insulingrowth factor 2 pathway regulates the extinction of fear memories. EMBO J 30:4071-4083.

Ajamian F, Salminen A, Reeben M (2004) Selective regulation of class I and class II histone deacetylases expression by inhibitors of histone deacetylases in cultured mouse neural cells. Neurosci Lett 365:64-68.

Amann LC, Gandal MJ, Halene TB, Ehrlichman RS, White SL, McCarren HS, Siegel SJ (2010) Mouse behavioral endophenotypes for schizophrenia. Brain Res Bull 30:147-161.

Bandyopadhyay D, Curry JL, Lin Q, Richards HW, Chen D, Hornsby PJ, Timchenko NA, Medrano EE (2007) Dynamic assembly of chromatin complexes during cellular senescence: implications for the growth arrest of human melanocytic nevi. Aging Cell 6:577-591.

Benes FM, Lim B, Matzilevich D, Walsh JP, Subburaju S, Minns M (2007) Regulation of the GABA cell phenotype in hippocampus of schizophrenics and bipolars. Proc Natl Acad Sci U S A 104:10164-10169.

Bousiges O, Vasconcelos AP, Neidl R, Cosquer B, Herbeaux K, Panteleeva I, Loeffler JP, Cassel JC, Boutillier AL (2010) Spatial memory consolidation is associated with induction of several lysine-acetyltransferase (histone acetyltransferase) expression levels and $\mathrm{H} 2 \mathrm{~B} / \mathrm{H} 4$ acetylation-dependent transcriptional events in the rat hippocampus. Neuropsychopharmacology 35: 2521-2537.

Bouton ME (2004) Context and behavioral processes in extinction. Learn Mem 11:485-494.

Bredy TW, Barad M (2008) The histone deacetylase inhibitor valproic acid enhances acquisition, extinction, and reconsolidation of conditioned fear. Learn Mem 15:39-45.

Bredy TW, Wu H, Crego C, Zellhoefer J, Sun YE, Barad M (2007) Histone modifications around individual BDNF gene promoters in prefrontal cortex are associated with extinction of conditioned fear. Learn Mem 14:268-276.

Broide RS, Redwine JM, Aftahi N, Young W, Bloom FE, Winrow CJ (2007) Distribution of histone deacetylases $1-11$ in the rat brain. J Mol Neurosci 31:47-58.

David G, Grandinetti KB, Finnerty PM, Simpson N, Chu GC, Depinho RA (2008) Specific requirement of the chromatin modifier mSin3B in cell cycle exit and cellular differentiation. Proc Natl Acad Sci USA 105:4168-4172.

Delamater AR (2004) Experimental extinction in Pavlovian conditioning: behavioural and neuroscience perspectives. Q J Exp Psychol B 57:97-132.

Fischer A, Tsai LH (2008) Counteracting molecular pathways regulating the reduction of fear: implications for the treatment of anxiety diseases. In: Post-traumatic stress disorders: basic science and clinical practice (Shiromani PJ, Keane TM, LeDoux JE, eds), pp 75-104. New York: Humana.

Fischer A, Sananbenesi F, Schrick C, Spiess J, Radulovic J (2004) Distinct roles of hippocampal de novo protein synthesis and actin rearrangement in extinction of contextual fear. J Neurosci 24:1962-1966.

Fischer A, Sananbenesi F, Wang X, Dobbin M, Tsai LH (2007) Recovery of learning and memory after neuronal loss is associated with chromatin remodeling. Nature 447:178-182.

Fischer A, Sananbenesi F, Mungenast A, Tsai LH (2010) Targeting the right HDAC(s) to treat cognitive diseases. Trends Pharmacol Sci 31:605-617.

Fontán-Lozano A, Romero-Granados R, Troncoso J, Múnera A, DelgadoGarcía JM, Carrión AM (2008) Histone deacetylase inhibitors improve learning consolidation in young and in KA-induced-neurodegeneration and SAMP-8-mutant mice. Mol Cell Neurosci 39:193-201.

Gregoretti IV, Lee YM, Goodson HV (2004) Molecular evolution of the histone deacetylase family: functional implications of phylogenetic analysis. J Mol Biol 338:17-31.

Guan JS, Haggarty SJ, Giacometti E, Dannenberg JH, Joseph N, Gao J, Nieland TJ, Zhou Y, Wang X, Mazitschek R, Bradner JE, DePinho RA, Jaenisch R, Tsai LH (2009) HDAC2 negatively regulates memory formation and synaptic plasticity. Nature 459:55-60.

Harrison MR, Georgiou AS, Spaink HP, Cunliffe VT (2011) The epigenetic regulator Histone Deacetylase 1 promotes transcription of a core neurogenic programme in zebrafish embryos. BMC Genomics 12:24.

Holt DJ, Lebron-Milad K, Milad MR, Rauch SL, Pitman RK, Orr SP, Cassidy BS, Walsh JP, Goff DC (2009) Extinction memory is impaired in schizophrenia. Mol Psychiatry 65:455-463.

Hu E, Dul E, Sung CM, Chen Z, Kirkpatrick R, Zhang GF, Johanson K, Liu R, Lago A, Hofmann G, Macarron R, de los Frailes M, Perez P, Krawiec J, Winkler J, Jaye M (2003) Identification of novel isoform-selective inhibitors within class I histone deacetylases. J Pharmacol Exp Ther 307:720-728.

Jawhar S, Trawicka A, Jenneckens C, Bayer TA, Wirths O (2012) Motor deficits, neuron loss, and reduced anxiety coinciding with axonal degeneration and intraneuronal Abeta aggregation in the 5XFAD mouse model of Alzheimer's disease. Neurobiol Aging 33:196.e29-e40.

Jepsen K, Rosenfeld MG (2002) Biological roles and mechanistic actions of corepressor complexes. J Cell Sci 15:689-698.

Khan N, Jeffers M, Kumar S, Hackett C, Boldog F, Khramtsov N, Qian X, Mills E, Berghs SC, Carey N, Finn PW, Collins LS, Tumber A, Ritchie JW, Jensen PB, Lichenstein HS, Sehested M (2008) Determination of the class and isoform selectivity of small-molecule histone deacetylase inhibitors. Biochem J 409:581-589.

Kimura A, Matsubara K, Horikoshi M (2005) A decade of histone acetylation: marking eukaryotic chromosomes with specific codes. J Biochem 138:647-662.

Kouzarides T (2007) Chromatin modifications and their function. Cell 128:693-705.

Krauss V (2008) Glimpses of evolution: heterochromatic histone H3K9 methyltransferases left its marks behind. Genetica 133:93-106.

Kuczera T, Stilling RM, Hsia HE, Bahari-Javan S, Irniger S, Nasmyth K, Sananbenesi F, Fischer A (2011) The anaphase promoting complex is required for memory function in mice. Learn Mem 18:49-57.

Kügler S, Lingor P, Schöll U, Zolotukhin S, Bähr M (2003) Differential transgene expression in brain cells in vivo and in vitro from AAV-2 vectors with small transcriptional control units. Virology 311:89-95.

Lattal KM, Barrett RM, Wood MA (2007) Systemic or intrahippocampal delivery of histone deacetylase inhibitors facilitates fear extinction. Behav Brain Res 121:1125-1131.

Levenson JM, O’Riordan KJ, Brown KD, Trinh MA, Molfese DL, Sweatt JD (2004) Regulation of histone acetylation during memory formation in the hippocampus. J Biol Chem 279:40545-40559.

Liu S, Wu LC, Pang J, Santhanam R, Schwind S, Wu YZ, Hickey CJ, Yu J, Becker H, Maharry K, Radmacher MD, Li C, Whitman SP, Mishra A, Stauffer N, Eiring AM, Briesewitz R, Baiocchi RA, Chan KK, Paschka P, et al. (2010) Sp1/NFkappaB/HDAC/miR-29b regulatory network in KIT-driven myeloid leukemia. Cancer Cell 17:333-347.

McQuown SC, Barrett RM, Matheos DP, Post RJ, Rogge GA, Alenghat T, Mullican SE, Jones S, Rusche JR, Lazar MA, Wood MA (2011) HDAC3 is a critical negative regulator of long-term memory formation. J Neurosci 31:764-774. 
Murayama A, Ohmori K, Fujimura A, Minami H, Yasuzawa-Tanaka K, Kuroda T, Oie S, Daitoku H, Okuwaki M, Nagata K, Fukamizu A, Kimura K, Shimizu T, Yanagisawa J (2008) Epigenetic control of rDNA loci in response to intracellular energy status. Cell 133:627-639.

Myers KM, Davis M (2007) Mechanisms of fear extinction. Mol Psychiatry $12: 120-150$

Peirce JL, Chesler EJ, Williams RW, Lu L (2003) Genetic architecture of the mouse hippocampus: identification of gene loci with selective regional effects. Genes Brain Behav 2:238-252.

Peleg S, Sananbenesi F, Zovoilis A, Burkhardt S, Bahari-Javan S, Agis-Balboa RC, Cota P, Wittnam JL, Gogol-Doering A, Opitz L, Salinas-Riester G, Dettenhofer M, Kang H, Farinelli L, Chen W, Fischer A (2010) Altered histone acetylation is associated with age-dependent memory impairment in mice. Science 328:753-756.

Qiang M, Denny A, Lieu M, Carreon S, Li J (2011) Histone H3K9 modifications are a local chromatin event involved in ethanol-induced neuroadaptation of the NR2B gene. Epigenetics. Advance online publication. Retrieved December 9, 2011. doi: org/10.4161/epi.6.9.16924.

Quinti L, Chopra V, Rotili D, Valente S, Amore A, Franci G, Meade S, Valenza M, Altucci L, Maxwell MM, Cattaneo E, Hersch S, Mai A, Kazantsev A (2010) Evaluation of histone deacetylases as drug targets in Huntington's disease models. Study of HDACs in brain tissues from R6/2 and CAG140 knock-in HD mouse models and human patients and in a neuronal HD cell model. PLoS Curr 2:RRN1172.

Radulovic J, Kammermeier J, Spiess J (1998) Relationship between fos production and classical fear conditioning: effects of novelty, latent inhibition, and unconditioned stimulus preexposure. J Neurosci 18:7452-7461.

Radyushkin K, Hammerschmidt K, Boretius S, Varoqueaux F, El-Kordi A, Ronnenberg A, Winter D, Frahm J, Fischer J, Brose N, Ehrenreich H (2009) Neuroligin-3-deficient mice: model of a monogenic heritable form of autism with an olfactory deficit. Genes Brain Behav 8:416-425.

Renthal W, Carle TL, Maze I, Covington HE 3rd, Truong HT, Alibhai I, Kumar A, Montgomery RL, Olson EN, Nestler EJ (2008) Delta FosB mediates epigenetic desensitization of the c-fos gene after chronic amphetamine exposure. J Neurosci 28:7344-7349.

Sananbenesi F, Fischer A (2009) The epigenetic bottleneck of neurodegenerative and psychiatric diseases. Biol Chem 390:1145-1153.
Sananbenesi F, Fischer A, Wang X, Schrick C, Neve R, Radulovic J, Tsai LH (2007) A hippocampal Cdk5 pathway regulates extinction of contextual fear. Nat Neurosci 10:1012-1019.

Schotta G, Ebert A, Reuter G (2003) SU(VAR)3-9 is a conserved key function in heterochromatin silencing. Genetica 117:149-158.

Sharma RP, Grayson DR, Gavin DP (2008) Histone deacetylase 1 expression is increased in the prefrontal cortex of schizophrenia subjects: analysis of the National Brain Databank microarray collection. Schizophr Bull 98:111-117.

Simonini MV, Camargo LM, Dong E, Maloku E, Veldic M, Costa E, Guidotti A (2006) The benzamide MS-275 is a potent, long-lasting brain regionselective inhibitor of histone deacetylases. Proc Natl Acad Sci U S A 103:1587-1592.

Tronson NC, Schrick C, Guzman YF, Huh KH, Srivastava DP, Penzes P, Guedea AL, Gao C, Radulovic J (2009) Segregated populations of hippocampal principal CA1 neurons mediating conditioning and extinction of contextual fear. J Neurosci 29:3387-3394.

Usenko T, Kukushkin A, Pospelova T, Pospelov V (2003) Transient expression of E1A and Ras oncogenes causes downregulation of c-fos gene transcription in nontransformed REF52 cells. Oncogene 22:7661-7666.

Vaquero A, Scher M, Erdjument-Bromage H, Tempst P, Serrano L, Reinberg D (2007) SIRT1 regulates the histone methyl-transferase SUV39H1 during heterochromatin formation. Nature 450:440-444.

Vaute O, Nicolas E, Vandel L, Trouche D (2002) Functional and physical interaction between the histone methyl transferase Suv39H1 and histone deacetylases. Nucleic Acids Res 30:475-481.

Wang Z, Yang D, Zhang X, Li T, Li J, Tang Y, Le W (2011) Hypoxia-induced downregulation of neprilysin by histone modification in mouse primary cortical and hippocampal neurons. PLoS One 6:e19229.

Yang SH, Vickers E, Brehm A, Kouzarides T, Sharrocks AD (2001) Temporal recruitment of the $\mathrm{mSin} 3 \mathrm{~A}$-histone deacetylase corepressor complex to the ETS domain transcription factor Elk-1. Mol Cell Biol 21:28022814.

Zovoilis A, Agbemenyah HY, Agis-Balboa RC, Stilling RM, Edbauer D, Rao P, Farinelli L, Delalle I, Schmitt A, Falkai P, Bahari-Javan S, Burkhardt S, Sananbenesi F, Fischer A (2011) microRNA-34c is a novel target to treat dementias. EMBO J 30:4299-4308. 